The attainment of a soil temperature of $45^{\circ} \mathrm{F}$. $\left(7 \cdot 2^{\circ}\right.$ C. $)$, for example, imposes an initial limit to the activity of larvæ of the potato root eolworm, with no such limit to growth in the early Epicure potatohost. This has important economic and pathological repercussions, and the growth of such early crops provides, moreover, the only cultural possibility of obtaining even moderate yields on infested land. Low incidence of club root disease of swedes is associated with a relatively high soil temperature in July, relatively high amounts of bright sunshine in June, July and September, relatively low rainfall in September, and relatively high rainfall in October. The effect of bright sunshine on disease can only arise through its effect on the host. Practical measures for the grower would be to control soil moisture in September and October.

A second paper by Dr. Grainger, in which he had collaborated with J. L. Sneddon, E. de C. Chisholm and A. Hastie (Auchincruive), reported that higher yields of barley grain are related to lower maximum air temperature and higher rainfall in June. Tho production of bean grain is stimulated by higher average maximum air temperature in May, lower bright sunshine in June, and higher rainfall in July. Yields of oat grain are higher with lower average air temperature in July, and wheat grain with lower average air temperature in April and higher rainfall in July. Winter varieties of wheat give higher yields of grain when, in addition to these correlations with climate in April and July, there is a lower amount of bright sunshine in March. The practical value of the results lies in the precision they bring in sug. gesting that conservation of soil moisture is most necessary in particular months for each crop in a given area.

Dr. F. L. Waterhouse (University College, Dundee; University of St. Andrews) gave detailed assessments of seasonal and diurnal differences in climate within grass crops, with the view of their suitability for the development and successful existence of insects. The differences are mainly related to the height, density and mode of growth of the crop and also to the angle of the sun's rays. A matted basal layer of dead grass in wild grassland, or the co-existence of a clover crop in hay and silage fields, maintains a cool humid atmosphere next to the ground. This is favourable to insects when more arid conditions exist at higher levels, where wind speed is the most significant factor. These varying conditions can make available to an insect a considerable range of body temperatures and states of water-loss during periods of insolation. The presence of broad-leaved weeds can interfere with the relatively uniform habitat presented by pure grassland.

A preliminary report on continuous records of profile soil temperatures within an afforested area was given by Dr. J. R. H. Coutts (Soil Science Department, University of Aberdeen), who said that mean annual temperatures were found to be practically the same throughout the soil profile, but that inversions of the profile occurred in April and August. Future results from this study should yield information of considerable importance. Mr. J. M. Caborn (Forestry Department, University of Edinburgh) reviewed work on the effect of shelter belts on the climate of the areas influenced by them. $\mathrm{He}$ laid stress upon the density of the shelter. A completely dense belt, for example, is 80 per cent ineffective at 10 heights away in the lee, whereas a less-dense belt is effective 15 heights away, and a density of 50 per cent has been found to be the most effective. In detail the temperature in the lee of a shelter belt is often $1^{\circ} \mathrm{F}$. higher than in the open, during the day; relative humidity is about 3 per cent less in the lee, and soil moisture is about 1 per cent higher in this area. Crop yields have also been found to be higher in the lee of shelter belts.

Mr. F. H. D. Green (Nature Conservancy) considered the importance of climate and climatic studies on the ecological work of the Conservancy. One important conclusion is that the climate and conditions in mountain-top valleys should not be considered on a basis of their floor altitude, but as part of the mountain top itself. An indirect effect of summer rainfall on the response to phosphatic fertilizers was mentioned by Dr. A. M. Smith and Dr. K. Simpson (East of Scotland College of Agriculture, Edinburgh). It is fairly common knowledge that response to phosphatic fertilizers tends to be small in a dry season and high in a wet one. It was found, however, that the percentage recovery of phosphorus is more closely related to soil $p \mathrm{H}$ than to summer rainfall. The correlation between phosphate recovery and soil $p \mathrm{H}$ is, nevertheless, much more significant when the effects of summer rainfall are eliminated.

The symposium served a most useful purpose. Biologists and meteorologists have remained separate for too long, and it is to be hoped that this conscious joining of their forces may be followed by further similar meetings.

\section{ROYAL GREENWICH OBSERVATORY}

\section{ANNUAL REPORT FOR 1953-54}

$\mathrm{T}$

HE annual report of the Astronomer Royal for the period May 1, 1953-April 30, 1954 deals as usual with three separate sections of the Royal Greenwich Observatory in Greenwich, Abinger and Herstmonceux*. The Greenwich Octagon Room, which was formally opened on May 8, 1952 (referred to in last year's report), is accessible to the public, and Halley's transit and Bradley's zenith sector are displayed in the room, as well as copies of various old prints of the Observatory. A considerable amount of work has been done to the New Building, and the hot-air furnaces have been overhauled; repair and maintenance work has been carried out in the old buildings, and the boundary fences have been repaired and strengthened. A new boiler has been installed for heating the Record Rooms and Time Department Office.

The Yapp 36-in. reflector has been used with the single-prism spectrograph in continuation of observations of the standard stars of the Yerkes Atlas, and 86 spectra of 74 stars have been secured. During October 30-April 26, while the 21-ft. eclipse telescope was under test, the instrument was out of use. In last year's report reference was made to the proposal to televise Jupiter and its satellites, and on January 13 the scheme was carried out with great success; unfortunately, the next night, on which a full-scale programme was scheduled, was cloudy, and a 'standby programme' had to be substituted.

* Report of the Astronomer Royal to the Board of Visitors of the Royal Greenwich Observatory, Read at the Annual Visitation of the Royal Observatory, June 12, 1954. Pp. 30. (Herstmonceux : Royal Greenwich Observatory, 1954.) 
Observations at the Magnetic Observatory, Abinger, are so disturbed by the local electric railways that the Board of Admiralty has approved, in principle, its removal to a site near Hartland, North Devon. It is highly desirable that observations in the new site should begin not later than the middle of 1957, and an overlap of observations with those at Abinger of at least a year will, it is hoped, include the International Geophysical Year. If it does, the magnetic data for that year would then include results from two observatories in the south of England and from the two northern observatories at Lerwick and Eskdalemuir.

While substantial progress in the removal to Herstmonceux has been made, it is disappointing that delays in the construction of the meridian group of buildings have taken place; the transit circle building is still unusable, and the photographic zenith tube building has only reached the foundation stage. The decision by the Admiralty that no official houses for the observing staff will be provided at Herstmonceux increases the need for close coordination between the building programme at the Observatory and the provision of houses for the staff through the local Rural District Council. The delay in the completion of the consulting architect's plans for the buildings to house the Time Department, the Nautical Almanac Office and the workshops will still further postpone the date of the removal.

Mr. J. Evershed has presented the Observatory with the principal parts of his solar spectroscopo from his private observatory at Ewhurst; these include a cœlostat for a 15-in. mirror, a train of three large liquid prisms and many accessory items. $\mathrm{He}$ had previously presented the Observatory with a pair of large solid glass prisms of $45^{\circ}$ angle and a $2 \mathrm{l}-\mathrm{ft}$. collimator lens. The large reflecting prism of $30^{\circ}$ angle which the Royal Society had lent him has been transferred to the Observatory.

Cosmic ray recording with the Clintel apparatus has been continued, but some of the data obtained were unreliable: some modification of the apparatus has, in consequence, been done. The investigations of the atmospheric cosmic-ray Cerenkov effect have been discontinued because the slit in the solar dome was found to be too narrow for a satisfactory arrangement. A project of high-energy shower recording has been given some consideration.

The "Nautical Almanac" for 1955, which was published in April, contains a list of observatories, the first it has given since 1941, and, generally speaking, the list is confined to those observatories of which the work demands $\approx$ knowledge of accurate values of the geographical co-ordinates. To comply with the recommendations of the International Astronomical Union made at the Eighth General Assembly in Rome in 1952, the first part of the "Nautical Almanac" for 1960 has been completely redesigned, and preparations of copy for 1960 will soon be started. Good progress has been made in the calculation of the ephemerides of the sun and planets for the years $1960-80$. In the report of the Observatory for 1952-53, reference was made to the preparation of illustrative examples for the use of different methods of calculating perturbations of comets and minor planets for the third volume of "Planetary Co-ordinates", and Encke's method has been completed, while Hansen's method is noarly finished. Somo progress has been made with the method of variation of elements and with Herrick's method of variation of parameters. In connexion with the "Star Almanac", the 1955 edition of which is expected to appear in June, it is interesting to know that it is now an established success and that reprints have been necessary in 1953 and 1954 in spite of printing increased numbers.

The figuring of the 98-in. disk of the Isaac Newton telescope has been suspended pending further tests in August during the works holiday period, when there will be an absence of vibration from heavy machinery. The broad features of the design of the mounting have been decided: it will be an offset fork mounting with polar axis in the form of an inverted and truncated cone.

\section{INDIAN ASSOCIATION FOR THE CULTIVATION OF SCIENCE}

\section{ANNUAL REPORT FOR 1953-54}

$T$

HE annual general meeting of the Indian Association for the Cultivation of Science was held on July 30 at Jadavpur, Calcutta. Prof. P. Ray, acting director, in presenting the annual report on the Association for 1953-54, said that the six research departments, the library, the workshop and the administrative office continued to function actively for the third year in the new research laboratory building at Jadavpur. The Association has prepared a five-year plan of development, covering the financial years 1954-59, which envisages, for the existing departments, the expansion of facilities with respect to equipment and staff so as to consolidate the present research activities and also improve the level of efficiency, but does not involve establishment of any new department. For the five years 1954-59, the non-recurring requirements of the Association for equipment, standard reference books, etc., have been worked out at Rs. 1,138,200, and the projected development under land and building would involve an expenditure of Rs. $1,771,393$. During the same period the normal recurring grant for running the Association will have to be increased from Rs. 465,630 in 1954-55 to Rs. 777,415 , thus requiring a total sum of Rs. 3,227,592 for the entire five-year period. It is expected that the Association's non-recurring demand will be met by the Government of India and the Government of West Bengal in the proportion of $2: 1$. The present recurring charges will continue to be borne by the Government of India, and it is expected that the additional requirements will be also borne by the Governments of India and of West Bengal in the proportion already mentioned.

Prof. Ray reported that the Association has under operation four research schemes of the Council of Scientific and Industrial Research of the Government of India, three research schemes under Prof. S. R. Palit and one under Prof. B. N. Srivastava. The Government of India, through the Ministry of Natural Resources and Scientific Research, has established a number of senior and junior scholarships for providing research training to deserving students at the Association under the Scientific Man-Power Committee Scheme.

During the year the Association started a publication section and undertook the publication of a number of books and monographs, including a book on the history of science in Bengali, "Bijnaner 